\title{
O TEATRO DE RUA BRASILEIRO COMO ARTE PÚBLICA: A MEGERA DOMADA DO GRUPO UEBA ${ }^{1}$
}

\author{
Anna Stegh Camati
}

Introdução

Em seu recente livro, Extramural Shakespeare (2010), Denise Albanese argumenta que a posição de Shakespeare na cultura americana mudou nos anos próximos à virada do milênio. Esse autor não está mais situado no topo da cultura erudita, mas tornou-se propriedade pública. Pegando emprestado do ensaio "O que é um autor?” (1969), de Michel Foucault, que desmistifica a autoria e estabelece o conceito denominado função-autor, Albanese cria um termo análogo — função-Shakespeare - para explicar "a soma dos inúmeros papéis que Shakespeare desempenha e é levado a desempenhar institucional e publicamente" (p. 5) na contemporaneidade.

As experiências interculturais bem-sucedidas de Eugenio Barba, Peter Brook e Ariane Mnouchkine têm incentivado grupos brasileiros de teatro, cujos participantes geralmente são oriundos do meio acadêmico, a dessacralizar ou a abrasileirar Shakespeare, rejeitando práticas teatrais ortodoxas e apresentando as peças desse autor a céu aberto, como arte pública, fora dos muros da academia.

A proposta deste trabalho é discutir o surgimento de produções shakespearianas no teatro de rua brasileiro, seguindo a tendência contemporânea de popularização do poeta, o que também foi realizado pela indústria do cinema, pelas graphic novels, pelas novas mídias e por outras manifestações da cultura popular e de massa.

\footnotetext{
${ }^{1}$ Trabalho apresentado no the 2013 Congress of the Latin American Studies Association (LASA), realizado de 20 de maio a 01 de junho de 2013 em Washington, DC. Título original: "Brazilian Street Theatre as Public Art: Ueba's The Taming of the Shrew". Tradução para o português de Thelma Christina Ribeiro Côrtes.
} 
CAMATI - O teatro de rua brasileiro como arte pública...

\section{Encenações ao ar livre: quando o lugar se torna espaço teatral}

$\mathrm{Na}$ horinha, mesmo; este lugar é maravilhosamente conveniente para o nosso ensaio. O gramado, aqui, vai ser nosso palco, esse arbusto de espinhos, nossa coxia [...]..$^{2}$ SHAKESPEARE, SONHO DE UMA NOITE DE VERÃO

De acordo com Michel de Certeau (2010), lugar é um local fixo, em oposição a espaço, que é socialmente construído: embora uma rua possa ser idealizada pelo planejamento urbano, ela dependerá de movimento, de mudança e de interação para se transformar em espaço ativo. O estudioso francês alega que "o espaço é um lugar praticado" (p. 119) que adquire uma dinâmica sui generis, tornando-se espaço quando apropriado para fins específicos durante um período de tempo. Assim, quando uma peça é apresentada em locais públicos, o lugar escolhido, por um curto período de tempo, torna-se espaço teatral, como é afirmado por Pedro Quina ${ }^{3}$ no prólogo da cena de ensaio de Sonho de uma noite de verão (1595-1596), citado na epígrafe. Ou, como Peter Brook (1968) teoriza em The Empty Space: "Posso escolher qualquer espaço vazio e considerá-lo um palco nu. Um homem atravessa este espaço enquanto outro observa. Isto é suficiente para criar uma ação cênica",4 (p. 9).

Encenar ao ar livre é, na verdade, voltar às raízes do teatro: “Téspis se apresentava para as ágoras atenienses em uma carroça, no século VI a.C., e as peças medievais chamadas "mistérios" aconteciam no adro das igrejas e nas praças das cidades" (Pavis, 1998, p. 372). E mesmo durante a era elisabetana, as peças de Shakespeare foram muitas

\footnotetext{
${ }^{2}$ N.T. Tradução de Barbara Heliodora (SHAKESPEARE, William. Sonho de uma noite de verão. Tradução: Barbara Heliodora. Rio de Janeiro: Lacerda Ed., 2004. 128p.).

${ }^{3}$ N.T. Os nomes em português dos personagens shakespearianos citados neste artigo seguem as traduções de Barbara Heliodora.

${ }^{4}$ N.T. As traduções das citações do livro de Peter Brook foram extraídas da edição brasileira: BROOK, Peter. O teatro e seu espaço. Tradução: Oscar Araripe e Tessy Calado. Petrópolis: Ed. Vozes, 1970. Disponível em: <http://pt.scribd.com/doc/20061686/O-Teatro-e-seu-espaco-Peter-Brook>
} 
CAMATI - O teatro de rua brasileiro como arte pública...

vezes representadas em espaços a céu aberto, principalmente quando a grande peste de Londres se tornou uma epidemia e os teatros tiveram de ser fechados para evitar o contágio.

Nos dias de hoje, encenar Sakespeare ao ar livre parece ter se tornado novamente uma tendência mundial. Enquanto na Grã-Bretanha montar peças desse autor a céu aberto é um movimento que inclui tanto companhias profissionais quanto amadoras - envolvendo desde grandes companhias profissionais, como a New Shakespeare Company, sediada no Open-Air Theatre, situado no Regent's Park, em Londres [...] até grupos amadores pequenos, como o The Villagers, perto de Gosport, em Hampshire [...]" (Dobson, 2011, p. 155) —, no Brasil, produções shakespearianas de teatro de rua são realizadas sobretudo por grupos profissionais de teatro.

\section{Montagens a céu aberto de Shakespeare no Brasil}

O Brasil assistiu a uma expansão considerável de produções shakespearianas nas duas últimas décadas. Pretendo argumentar que, no teatro de rua brasileiro, Shakespeare assume uma função semelhante àquela atribuída ao Public Theatre de Joseph Papp, que, como Albanese (2010) coloca, é "famoso por sua ambição de dessacralizar Shakespeare e tornar suas peças acessíveis a públicos não-elitizados” (p. 40).

Desde os anos 1990, grupos de teatro de diferentes regiões brasileiras, tais como o Grupo Galpão (Minas Gerais), o Grupo de Teatro Clowns de Shakespeare (Rio Grande do Norte) e o Grupo Ueba Produtos Notáveis (Rio Grande do Sul), tendem a renegociar a função-Shakespeare no Brasil, deslocando o legado deste autor da esfera da elite. Seu principal objetivo é adaptar as peças do poeta para públicos populares, apresentando-as nas ruas, praças, parques, mercados públicos e em outros locais de fácil acesso e de grande circulação de pessoas. Além de criarem um local lúdico que, por um breve período de tempo, quebra a rotina e a ordem cotidianas da cidade, esses grupos também proporcionam uma experiência socialmente libertadora para pessoas de todas as classes sociais que democraticamente se reúnem como uma comunidade —, até mesmo para aquelas que não frequentam teatros. 
CAMATI - O teatro de rua brasileiro como arte pública...

Um papel decisivo foi desempenhado pelo Grupo Galpão, uma companhia de teatro de rua do sudeste brasileiro, fundada em 1982, cujo espetáculo inovador Romeu e Julieta, dirigido por Gabriel Villela, foi encenado com sucesso duas vezes no Globe Theatre de Londres (2000 e 2012). Vale a pena mencionar, porém, que esse espetáculo intercultural foi inicialmente planejado para as ruas e encenado ao ar livre, no Brasil e em outros países, e que só muito tempo depois foi adaptado para ambientes fechados. Influenciado por tendências que encaram o teatro como um espaço de reciclagem cultural e de negociação entre o global e o local, o Grupo Galpão desenvolveu uma estética híbrida de interpretação, apropriando-se livremente de elementos de arte erudita e da cultura popular, misturando e combinando formas, gêneros e estilos múltiplos, principalmente "o movimento de vanguarda do teatro contemporâneo com a produção do imaginário regional-cultural inscrito no código performativo brasileiro [...]" (Alves \& Noe, 1999, p 265-266).

No Nordeste, a companhia de teatro mais prolífica - seguindo o caminho da comédia shakespeariana a céu aberto - é a Clowns de Shakespeare, com sede em Natal, que tem trabalhado de forma colaborativa desde 1993. Sonho de uma noite de verão (1993), Noite de Reis (1994), A megera do nada (1996 - título proposto para A megera domada) e Muito barulho por quase nada (2003 - título proposto para Muito barulho por nada) fazem parte do repertório de apresentações de rua dessa companhia. Em 2010, ela adaptou Ricardo III (sob o título Sua Incelença, Ricardo III) para locais ao ar livre, um empreendimento arriscado, porque peças históricas têm a reputação de serem pouco palatáveis para plateias populares no Brasil. Com essa produção, que acabou sendo muito bem sucedida, a Clowns de Shakespeare alcançou reconhecimento nacional e internacional (Camati \& Leão, 2011).

Tanto o Grupo Galpão quanto a Clowns de Shakespeare valem-se de uma ampla gama de formas de arte e de práticas de atuação, tais como o teatro de rua, rotinas circenses, máscaras e técnicas físicas herdadas da commedia dell'arte, o discurso intercultural do teatro contemporâneo, mímica, teatro de fantoches, dança e música. Além de se apropriarem de técnicas experimentais mais sofisticadas, desenvolvidas por profissionais do teatro, tais como Bertolt Brecht, Jerzy Grotowski, Augusto Boal e Eugenio Barba, as duas 
CAMATI - O teatro de rua brasileiro como arte pública...

companhias também recriam convenções elisabetanas de palco e aspectos formais e estilísticos da dramaturgia de Shakespeare (Camati \& Leão, 2011).

\section{Reciclando Shakespeare: o Grupo Ueba como um estudo de caso}

O Grupo Ueba, localizado em Caxias do Sul (Rio Grande do Sul), foi fundado pelos atores Jonas Piccoli e Aline Zilli, e é uma das muitas companhias ativas de teatro de rua em turnê pelo Brasil e pela América Latina. Assim como o Grupo Galpão e a Clowns de Shakespeare, esse grupo desenvolve técnicas e métodos experimentais de atuação, retornando a fontes populares, com o objetivo de tornar sua arte acessível a todos.

Devido à sua experiência com dramaturgia shakespeariana em espaços alternativos, o diretor afro-brasileiro Jessé de Oliveira foi convidado pelo Grupo Ueba para dirigir o espetáculo de rua de A megera domada, de Shakespeare, que o grupo realizou em 2009. A produção anterior de Shakespeare dirigida por Oliveira, intitulada Hamlet sincrético (2006), que estreou no Hospital Psiquiátrico São Pedro, em Porto Alegre, promoveu um diálogo não só entre o global e o local, mas também entre a historicidade do prédio antigo e a realização cênica do momento, agregando a semântica do espaço aos conteúdos temáticos do texto (Camati, 2010).

No livro mais recente de Oliveira, Memória do teatro de rua em Porto Alegre, ele relata que a capital do Rio Grande do Sul é um dos principais polos de teatro de rua no Brasil. Um grande número de grupos, tais como o Ói Nóis Aqui Traveiz, a Oficina Pernade-Pau, a Trupe Bumba Meu Bobo, o Grupo Manjericão, o Bonecos Gigantes da Cidade, o De Pernas Pro Ar, dentre outros, tornaram-se parte da história do teatro de rua contemporâneo do Brasil. A maioria dos grupos mencionados recebem verbas de instituições governamentais para financiar suas intervenções políticas e/ou educacionais, planejadas para públicos populares, não-elitizados (Oliveira, 2010, p. 11).

Apesar de vários desses grupos terem experiência com peças de Shakespeare para as ruas, enfoco especificamente, neste trabalho, a exuberância, o excesso e a energia carnavalesca emanados por A megera domada (2009) do Grupo Ueba, uma adaptação livre de The Taming of the Shrew (1592), de Shakespeare, enriquecida por especificidades e 
CAMATI - O teatro de rua brasileiro como arte pública...

temas emprestados da commedia dell'arte, uma tradição teatral que teria influenciado Shakespeare durante sua vida.

O espetáculo de rua do Grupo Ueba pode ser equiparado ao teatro rústico, tal como definido por Peter Brook, um teatro cujo arsenal de recursos é ilimitado. Esse autor afirma que "é sempre o teatro popular que vem salvar a situação. Através dos tempos ele tem tomado muitas formas e todas com um só traço em comum - uma aspereza. Sal, suor, barulho, cheiro: o teatro que não está dentro de um teatro, um teatro em carroças, em vagões, sobre tripé de platéias em pé, bebendo, sentadas ao redor de mesas, platéias participando e respondendo ao espetáculo [...]” (Brook, 1968, p. 37). Ele acrescenta que tais espetáculos assumem seu "papel de libertador social, pois por sua própria natureza o teatro popular é anti-autoritário, antitradicional, antipomposo, antipretensioso” (p. 38).

O espetáculo agregou a maioria das características enumeradas por Brook em sua descrição de teatro rústico e aspectos privilegiados da commedia dell'arte: as técnicas de atuação cômicas/grotescas, caracterização estereotipada, improvisação e teatro de arena sem separação entre o público e os artistas.

Além de recriar o prólogo shakespeariano - os artistas ingleses viajantes foram transmutados em um grupo de atores da commedia dell'arte - , a produção de rua do Grupo Ueba complicou questões de identidade por tomar emprestado ideias e temas de Arlequim, servidor de dois patrões (1743), de Goldoni. Um ator foi utilizado para encarnar os papéis de Grúmio - o criado de Petruchio, responsável pela maior parte do humor pastelão, porque interpreta as falas de seu patrão de uma forma mais literal - e Biondello - o segundo criado de Lucêncio, que sempre faz exatamente o que lhe é mandado, e que finge não saber que Trânio, passando-se por Lucêncio, não é o seu verdadeiro patrão. $O$ versátil ator que interpretou os dois personagens trocava de máscaras idênticas, de cores distintas, para enfrentar os diferentes mestres, mas, na maioria das vezes, ele tendia a confundir máscara e papel, uma estratégia cômica que serviu como um dispositivo brechtiano de distanciamento, ressaltando o jogo de identidades trocadas. Além disso, como os personagens trocavam de máscaras, trajes e adereços na frente dos espectadores o tempo todo, as pessoas eram convidadas a refletir sobre a natureza fluida da identidade. 
CAMATI - O teatro de rua brasileiro como arte pública...

Outro recurso inventivo, utilizado para suprir a falta de uma segunda atriz para interpretar Bianca, foi a representação desta personagem por uma série de bonecas manipuladas pelos atores, uma invenção burlesca que gerou um comentário sobre sua própria natureza manipulativa: ela é representada, a princípio, como uma pequena e inexpressiva Barbie; depois, como uma boneca de pano, que cresce gradualmente em tamanho e é arrastada por toda parte; e, finalmente, alcança a forma de uma boneca inflável erótica.

O polêmico discurso final de Catarina foi drasticamente reduzido. No entanto, o tempo todo sua linguagem corporal contradizia sua fala, para dar indícios de que sua suposta domesticação era parte de um jogo de sedução e/ou de poder jogado e consentido pelo marido e pela esposa. No final, Petruchio e Catarina, depois de muitas tentativas frustradas de se beijar, tiram suas máscaras, que os impediam de desfrutar de seu relacionamento amoroso, uma rotina cômica que provocou risos e aplausos por parte dos espectadores.

\section{Comentários finais}

Apesar de Shakespeare não ser muito encenado a céu aberto no Brasil, desde os anos 1990 este autor tem assumido um lugar de destaque no repertório de importantes companhias de teatro de rua, como o Grupo Galpão, o Clowns de Shakespeare e o Grupo Ueba, dentre outros. Estes grupos profissionais de teatro são representantes de uma tradição rica não só em termos locais, mas também em uma escala global mais ampla, porque eles, de forma bem-sucedida, têm voltado a atribuir a Shakespeare o caráter público que ele tinha em sua época.

Enquanto o Grupo Galpão e o Grupo Clowns de Shakespeare estão mais preocupados com produções interculturais - optando por um tipo de expressão que incorpora as tradições populares da região que cada um representa -, o Grupo Ueba tende a explorar a dramaturgia shakespeariana para problematizar questões de classe, de gênero e de sexualidade, restaurando também, dessa forma, a esfera política do teatro de rua. Todas essas companhias realizam espetáculos que modificam temporariamente a paisagem 
urbana, transformando espaços urbanos em tribunas populares, nas quais os temas apresentados fornecem elementos para reflexão e entretenimento aos transeuntes que interrompem sua rotina cotidiana para se tornarem espectadores ativos.

\section{Referências}

ALBANESE, Denise. Extramural Shakespeare. New York: Palgrave Macmillan, 2010.

ALVES, Junia de Castro M.; NOE, Marcia. Life is an Inverted Circus: Grupo Galpão’s Romeu e Julieta Adapted from Pennafort's Translation of Shakespeare's. Ilha do Desterro, n. 36, p. 265-281, jan./jun. 1999. Disponível em: <http://www.periodicos.ufsc.br/index.php/desterro/article/view/8191/7547> Acessado em: 25.04.2013.

BROOK, Peter. The Empty Space. New York: Atheneum, 1968.

CAMATI, Anna Stegh. A dialética da transculturação do Grupo Caixa-Preta: Hamlet sincrético em espaço não convencional. SocioPoética, v. 1, n. 6, p. 11-20, jul./dez. 2010. Disponível em: 〈http://www.eduep.uepb.edu.br/sociopoetica>

CAMATI, A. S.; LEÃO, L. C. Brazilianizing Shakespeare for Popular Audiences: The Street Spectacle Sua Incelença, Ricardo III. Comunicação inédita apresentada no $40^{\text {th }}$ Annual Meeting of the Shakespeare Association of America (SAA). Boston: Westin Copley Place, 2012.

CERTEAU, Michel de. The Practice of Everyday Life. Trans. Steven F. Rendall. Berkeley/ Los Angeles: University of California Press, 2010.

DOBSON, Michael. Shakespeare and Amateur Performance: A Cultural History. Cambridge/New York: Cambridge University Press, 2011.

FOUCAULT, Michel. What is an Author? Trans. Donald F. Bouchard and Sherry Simon. In: BOUCHARD, Donald F. (Ed.). Language, Counter-Memory, Practice. Ithaca, New York: Cornell University Press, 1977. p. 124-127.

OLIVEIRA, Jessé. Memória do teatro de rua em Porto Alegre. Porto Alegre: Editora Ueba, 2010. 
CAMATI - O teatro de rua brasileiro como arte pública...

PAVIS, Patrice. Dictionary of the Theatre: Terms, Concepts and Analysis. Trans. Christine Shantz. Toronto/Buffalo: University of Toronto Press, 1998.

SHAKESPEARE, William. A Midsummer Night's Dream. Ed. Harold F. Brooks. The Arden Shakespeare. Second Series. London: Thomson Learning, 2003.

. The Taming of the Shrew. Ed. Barbara Hodgdon. The Arden Shakespeare. Third Series. London: Thomson Learning, 2010. 